\title{
Online Determination of Trace Amounts of Tannic Acid in Colored Tannery Wastewaters by Automatic Reference Flow Injection Analysis
}

\author{
Liang Wei \\ School of Environment and Resource, Southwest University of Science and Technology, Mianyang 621900, China \\ Correspondence should be addressed to Liang Wei, daiweiv@sohu.com \\ Received 5 January 2010; Accepted 24 February 2010 \\ Academic Editor: Peter Stockwell \\ Copyright (C) 2010 Liang Wei. This is an open access article distributed under the Creative Commons Attribution License, which \\ permits unrestricted use, distribution, and reproduction in any medium, provided the original work is properly cited.

\begin{abstract}
A simple, rapid and sensitive method was proposed for online determination of tannic acid in colored tannery wastewater by automatic reference flow injection analysis. Based on the tannic acid reduction phosphotungstic acid to form blue compound in $\mathrm{pH} 12.38$ alkaline solutions, the shade of blue compound is in a linear relation to the content of tannic acid at the point of the maximum absorption peak of $760 \mathrm{~nm}$. The optimal experimental conditions had been obtained. The linear range of the proposed method was between $200 \mu \mathrm{g} \mathrm{L}{ }^{-1}$ to $80 \mathrm{mg} \mathrm{L}^{-1}$ and the detection limit was $0.58 \mu \mathrm{g} \mathrm{L}^{-1}$. The relative standard deviation was $3.08 \%$ and $2.43 \%$ for $500 \mu \mathrm{g} \mathrm{L}^{-1}$ and $40 \mathrm{mg} \mathrm{L}^{-1}$ of tannic acid standard solution, respectively, $(n=10)$. The method had been successfully applied to determination of tannic acid in colored tannery wastewaters and the analytical results were satisfactory.
\end{abstract}

\section{Introduction}

Leather tanning is one of the polluting industrial sources in terms of both conventional and toxic parameters, which include COD, BOD, tannic acid, protein, grease, sulfide, chloride, chromium, suspended substances, and so on. Tannic acid is a natural phenolic compound and is widely used in leather tanning. It is one of the main persistent organic pollutants in leather wastewater, causing environmental pollution $[1,2]$. Tannic acid may interact with metal to form toxic tannic acid-metal compound. Tannic acid may also interact with toxicants in aquatic ecosystems and may change their toxicity [3]. Therefore, it is very important to determine tannic acid in wastewaters in order to evaluate water pollution from leather wastewaters. Several methods have been used for the determination of tannic acid such as spectrophotometry $[4,5]$, chemiluminescence $[6,7]$, fluorescence $[8,9]$, voltammetry $[10,11]$, liquid chromatography $[12,13]$, thin-layer chromatography [14], titration [15], protein precipitation [16], flow injection analysis [17], and so forth. However, some are troublesome, time-consuming, and expensive. Modern environmental monitoring calls for automatic, simple, rapid, and sensitive methods for online determination.
A rapid, simple and automatic method was proposed for online determination of tannic acid in colored tannery wastewater by automatic reference flow injection analysis. The proposed method is based on the fact that tannic acid can reduce phosphotungstic acid to form blue compound in alkaline solutions. In the Folin-Denis method, saturation sodium carbonate reacts with phosphoric acid to form carbon dioxide which will affect the determination of tannic acid. Thus, in the proposed method, the alkaline solution of sodium tetraborate-sodium hydroxide buffersolution is substituted for saturation sodium carbonate solution to avoid the formation of carbon dioxide. Compared with manual methods, the proposed method not only consumes small sample, reagent and little time but also eliminates the interference of the colority of samples without sample pretreatment.

\section{Experiment}

2.1. Apparatus. A model ZJ-la automatic analyzer developed and produced successfully by Professor Xinshen Zhang (Sichuan University, Chengdu, China) was used. The analyzer has the functions of flow injection analysis (FIA), ion chromatography, and automatic sample injection. The 


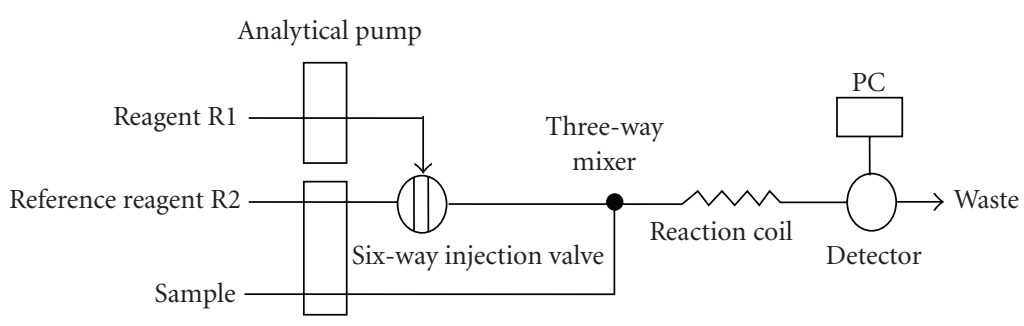

FIGURE 1: Schematic diagram of online determination of tannic acid.

function of flow injection analysis was applied to determine tannic acid. Two analytical pumps (Shanghai Huxi Analytical Instrument Plant, P.R. China) of flow injection were used to deliver all solutions. One was used to deliver reagent solution while the other delivered sample solution and reference reagent solution. Polytetrafluoroethylene (PTFE) tubing of $0.5 \mathrm{~mm}$ in internal diameter was used as the channels for all solutions to circulate.

Ultraviolet and visible spectrometer was obtained by using a Spectrumlab \$54 (Lengguang Technology Co., Shanghai, China). The absorbance intensity was recorded at $760 \mathrm{~nm}$ on an IBM-PC. Data acquisition and processing were performed with HW-2000 Chromatography software (Qianpu software Co., Ltd, Shanghai, China) running under Windows XP.

2.2. Reagents. All reagents used including sodium tungstate dihydrate, phosphomolybdicacid, tannic acid (Tianjin Ruijinte Chemical Reagent Plant, Tianjin, China), sodium tetraborate, sodium hydroxide, and phosphoric acid (Chengdu Fang Zhou Chemical Reagent Plant, Chengdu, China) were of analytical grade and all solutions were prepared with deionized water.

2.3. Preparation of Solution. Tannic acid stock standard solution: tannic acid stock standard solution at a concentration of $1000 \mathrm{mg} \mathrm{L}^{-1}$ was prepared by dissolving $1.000 \mathrm{~g}$ of tannic acid and diluting to $1000 \mathrm{~mL}$. Working solution was prepared by suitable dilution of the stock solution.

Phosphotungstic acid stock solution: phosphotungstic acid stock solution was prepared by dissolving $50 \mathrm{~g}$ sodium tungstate dihydrate, $10 \mathrm{~g}$ phosphomolybdicacid, and $25 \mathrm{~mL}$ of $85 \%$ phosphoric acid in $350 \mathrm{~mL}$ deionized water, distilling for 2 hours and then diluting to $500 \mathrm{~mL}$.

Reagent R1: $10 \mathrm{~mL}$ phosphotungstic acid stock solution was diluted to $500 \mathrm{~mL}$.

Reference reagent R2: $400 \mathrm{~mL}$ of $0.2 \mathrm{~mol} \mathrm{~L}^{-1}$ sodium tetraborate and $600 \mathrm{~mL}$ of $0.1 \mathrm{~mol} \mathrm{~L}^{-1}$ sodium hydroxide were mixed and the mixture diluted to $1000 \mathrm{~mL}$.

2.4. Analytical Procedure. The automatic reference FIA manifold used was outlined in Figure 1 with PTFE pipes. A smooth baseline was obtained when reference reagent $\mathrm{R} 2$ was injected into the six-way injection valve, mixed with sample in the three-way mixer, and pushed into the detector. When the instrument was set into "analyzing" position, reagent R1 was injected, mixed with reference reagent $\mathrm{R} 2$, and sample in the three-way mixer and reacted to form blue compound in the reaction coil. The blue compound was then carried into the detector. The absorbance intensity of the blue compound was determined at $760 \mathrm{~nm}$ by detector and transformed to a signal of the peak which was recorded by HW-2000 software on a PC.

\section{Results and Discussion}

3.1. Choice of the Detection Wavelength. In $\mathrm{pH} 12.38$ of sodium tetraborate and sodium hydroxide media, tannic acid reacts with reagent $\mathrm{R} 1$ and reference reagent $\mathrm{R} 2$ to form a blue compound. The absorbance of the blue compound was scanned in the range of $400-800 \mathrm{~nm}$ by ultravioletvisible spectrometer. The result showed that the maximum absorbance wavelength of the blue compound is $760 \mathrm{~nm}$.

3.2. Effect of Flow Rate. In the FIA, the flow rate could affect the sensitivity of the proposed method. In the study, the flow rate was adjusted by the internal diameter of pump pipe. Therefore, the effect of the flow rate of reagent R1, reference reagent $\mathrm{R} 2$, and sample on the peak height was studied from $0.10 \mathrm{~mL} \mathrm{~min}^{-1}$ to $1.00 \mathrm{~mL} \mathrm{~min}^{-1}$, respectively. The test results showed that the most peak height was obtained when the flow rates of reagent $\mathrm{R} 1$, reference reagent $\mathrm{R} 2$, and sample were $0.22 \mathrm{~mL} \mathrm{~min}^{-1}, 0.40 \mathrm{~mL} \mathrm{~min}^{-1}$, and $0.72 \mathrm{~mL} \mathrm{~min}^{-1}$, respectively.

3.3. Effect of Phosphotungstic Acid (Reagent R1). The reagent concentration was another important factor in flow injection analysis. The effect of amount of phosphotungstic acid on the peak height was tested from $0.2 \mathrm{~mL}$ to $4.0 \mathrm{~mL}$ (diluting to $100 \mathrm{~mL}$ ) in Figure 2. The results showed that the peak height rose when the amount of phosphotungstic acid changed from $0.2 \mathrm{~mL}$ to $1.5 \mathrm{~mL}$ (diluting to $100 \mathrm{~mL}$ ) and the peak height declined when amount of phosphotungstic acid changed from $1.5 \mathrm{~mL}$ to $4.0 \mathrm{~mL}$ (diluting to $100 \mathrm{~mL}$ ). Therefore, $1.5 \mathrm{~mL}$ (diluting to $100 \mathrm{~mL}$ ) of phosphotungstic acid were selected for further work.

According to the chemical reaction kinetics, the reaction rate will inevitably increase when concentrations of the reagent increase. Thus, the absorbency will increase when concentrations of phosphotungstic acid increase. However, the reaction rate will not increase when concentrations of the reagent reach a certain value. Therefore, when 


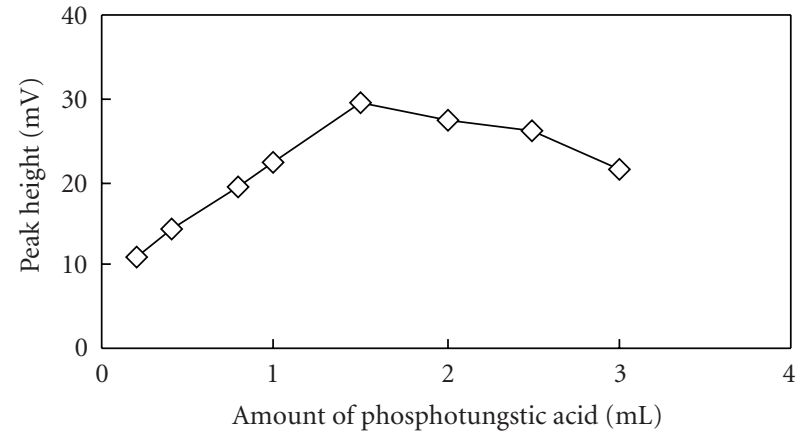

FIGURE 2: Effect of amount of phosphotungstic acid on the peak height.

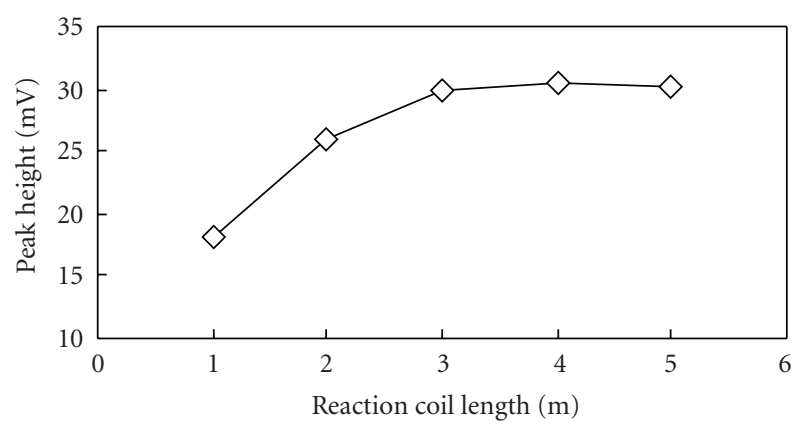

FIGURE 3: Effect of reaction coil length on the peak height.

phosphotungstic acid consumption reaches a certain value, the concentration of phosphotungstic acid which reacts with tannic acid should be certain because tannic acid concentration is fixed in the sample. Thereby, the absorbency will not increase when phosphotungstic acid concentration increases. On the contrary, the background color (baseline noises) will increase because the free state phosphotungstic acid in the system will increase.

3.4. Effect of $p H$. In the flow injection analysis, the absorbance of blue compound is affected by $\mathrm{pH}$ of the reaction medium. The effect of $\mathrm{pH}$ on the blue compound was tested in the $\mathrm{pH}$ range $4-13$. The test results showed that the maximum peak height could be obtained when $\mathrm{pH}$ was 12 or so. In the Folin-Denis method, saturation sodium carbonate reacts with phosphoric acid to form carbon dioxide which will affect the determination of tannic acid. Therefore, the $\mathrm{pH} 12.38$ alkaline solution of sodium tetraborate-sodium hydroxide solution (reference reagent R2) was selected to substitute for saturation sodium carbonate solution to avoid the formation of carbon dioxide in the proposed method.

3.5. Effect of the Reaction Coil Length. In the FIA, the reaction time is adjusted by the length of reaction coil. If reaction coil was too short, the reagents would react incompletely. If reaction coil was too long, it would be time-consuming. Therefore, reaction coil length from $1 \mathrm{~m}$ to $5 \mathrm{~m}$ was tested. The results in Figure 3 showed that $3 \mathrm{~m}$ of the reaction coil length was the optimum and any further increase of reaction coil length did not increase peak height. Thus, $3 \mathrm{~m}$ of the reaction coil length was chosen as optimal parameter.

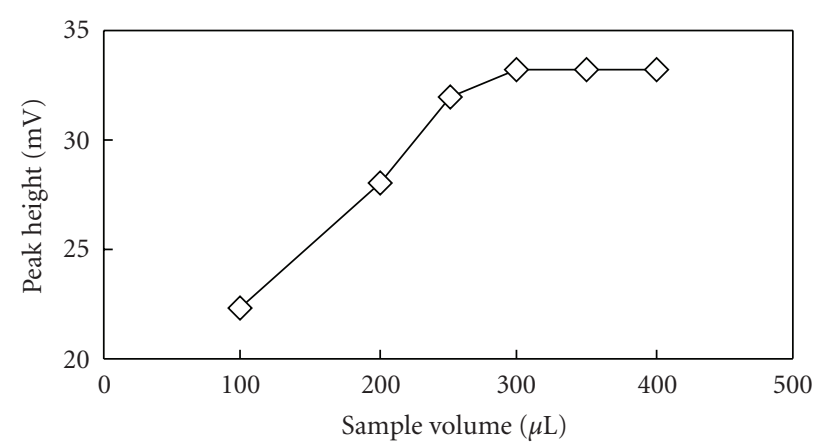

FIGURE 4: Effect of of sample volume on the peak height.

3.6. Effect of Sample Volume. Sample volume had a great effect on the peak height and sample frequency. Therefore, different sample volumes $(100,200,250,300,350,400 \mu \mathrm{L})$ were tested. The results in Figure 4 showed that the peak height rose when sample volume changed from $100 \mu \mathrm{L}$ to $300 \mu \mathrm{L}$ and peak height did not increase with further increase of sample volume. Therefore, $300 \mu \mathrm{L}$ of sample volume were selected for further work.

3.7. Effects of Foreign Ions. The interference of some possibly coexisting foreign ions was examined to make sure the proposed method can be applied to determine tannic acid in tannery wastewaters. The tolerance limit was defined as the concentration of added solutions causing less than $\pm 5 \%$ relative error during the determination of $500 \mu \mathrm{g} \mathrm{L}^{-1}$ tannic acid. No interference was observed except $\mathrm{SO}_{3}{ }^{2-}$. The interference was eliminated by heating the samples. The results showed that the proposed method had good selectivity. Therefore, the proposed method had good selectivity.

\subsection{Linearity, Precision, and Detection Limit of the Proposed} Method. To assess the reproducibility and accuracy of the proposed method, under the selected conditions above, tests of linearity, precision, and detection limit were conducted. The linearity was tested by a series of working standard solutions of tannic acid ranging from $100 \mu \mathrm{g} \mathrm{L} \mathrm{L}^{-1}$ to $100 \mathrm{mg} \mathrm{L}^{-1}$. Test showed that the peak height versus tannic acid concentration was linear within the range of $200 \mu \mathrm{g} \mathrm{L}$ to $20 \mathrm{mg} \mathrm{L}^{-1}$ and $20 \mathrm{mg} \mathrm{L}^{-1}$ to $80 \mathrm{mg} \mathrm{L}^{-1}$. The curves were $\mathrm{H}=5.2147 \mathrm{C}+1.3624$ and $\mathrm{H}=2.3485 \mathrm{C}+21.8542$, respectively, [H: peak height; $\mathrm{C}$ : concentration of tannic acid $\left.\left(\mathrm{mg} \mathrm{L}^{-1}\right)\right]$ and their correlation coefficients obtained were 0.9996 and 0.9997 , respectively. The detection limit ( 3 multiples of baseline noises) was $0.58 \mu \mathrm{g} \mathrm{L}^{-1}$. The test of precision was conducted by ten injections of $500 \mu \mathrm{g} \mathrm{L}^{-1}$ and $40 \mathrm{mg} \mathrm{L}^{-1}$ of tannic acid standard solution, respectively. The results showed that the relative standard deviation (RSD) was calculated as $3.08 \%$ and $2.43 \%$, respectively.

3.9. Application. The proposed method was applied to determine tannic acid in tannery wastewaters samples using the ZJ-la automatic analyzer. The results of samples were shown in Table 1. 
TABLE 1: Determination of tannic acid in tannery wastewater by the proposed method.

\begin{tabular}{lcccc}
\hline Sample & $\begin{array}{c}\text { Measured } \\
\left(\mathrm{mg} \mathrm{L}^{-1}\right)\end{array}$ & $\begin{array}{c}\text { Added } \\
\left(\mathrm{mg} \mathrm{L}^{-1}\right)\end{array}$ & $\begin{array}{c}\text { Found } \\
\left(\mathrm{mg} \mathrm{L}^{-1}\right)\end{array}$ & $\begin{array}{c}\text { Recovery } \\
(\%)\end{array}$ \\
\hline $1 \#$ & 20.59 & 20.00 & 41.83 & 106.2 \\
$2 \#$ & 18.73 & 20.00 & 39.05 & 101.6 \\
$3 \#$ & 21.22 & 20.00 & 40.74 & 97.6 \\
$4 \#$ & 4.32 & 5.00 & 9.14 & 96.4 \\
\hline
\end{tabular}

To prove the accuracy of the method, a test of recovery was conducted by accurately adding known concentration of tannic acid into each sample whose original tannic acid concentration had been determined. The test results in Table 1 showed that the recovery was between $96.4 \%$ and $106.2 \%$ and analytical results of the proposed method were satisfactory. Therefore, the proposed method was suitable for determination of tannic acid in tannery wastewaters.

\section{Conclusion}

The proposed method was significant with regard to the development of a rapid, simple, sensitive, and automatic analytical method for online determination of tannic acid. High sensitivity, broad determination range $\left(200 \mu \mathrm{g} \mathrm{L}^{-1}\right.$ to $80 \mathrm{mg} \mathrm{L}^{-1}$ of tannic acid), rapid testing, and fully automated analysis were just some of the advantages of the proposed method. Especially, compared with conventional methods, the proposed method not only consumed small sample and reagent but also eliminated the interference of the colority without sample pretreatment. The model ZJ-la automatic analyzer employed in this study is inexpensive, small and easily portable. The proposed method had been successfully applied to determine tannic acid in colored tannery wastewaters. The proposed method is suitable for determination of tannic acid in both colored and colourless tannery wastewaters for its good selectivity and the above mentioned advantages.

\section{Acknowledgment}

The author was very grateful for the sponsorship of Research Fund for the Doctoral Program of Southwest University of Science and Technology (Projection number: 08zx7120).

\section{References}

[1] L.-C. Chiang, J.-E. Chang, and S.-C. Tseng, "Electrochemical oxidation pretreatment of refractory organic pollutants," Water Science and Technology, vol. 36, no. 2-3, pp. 123-130, 1997.

[2] Q. Qin, "Pollution control on industrialization of gallotannin," Chemistry and Industry of Forest Products, vol. 28, no. 2, pp. 73-76, 2008.

[3] X. L. Oin and Y.-H. Liu, "Research and application of vegetable tannin in water treatment," Chinese Journal of Wastewater Treatment, vol. 26, no. 3, pp. 8-11, 2006.
[4] V. L. Dressler, E. L. Machado, and A. F. Martins, "Spectrophotometric determination of tannin in tanning effluent with a flow injection system," The Analyst, vol. 120, no. 4, pp. 11851188, 1995.

[5] N. Tinkílíc and A. Uyanílk, "Spectrophotometric determination of the tannin contents of various Turkish black tea, beer and wine samples," International Journal of Food Sciences and Nutrition, vol. 52, no. 3, pp. 289-294, 2001.

[6] C. G. Xie and H. Cui, "Detection of tannic acid at trace level in industrial wastewaters using a highly sensitive chemiluminescence method," Water Research, vol. 37, no. 1, pp. 233-237, 2003.

[7] B. G. T. Corominas, J. V. G. Mateo, L. L. Zamora, and J. M. Calatayud, "Determination of tannic acid by direct chemiluminescence in a FIA assembly," Talanta, vol. 58, no. 6, pp. 1243-1251, 2002.

[8] S. L. Feng, A. N. Tang, J. H. Jiang, and J. Fan, "Spectrofluorimetric determination of tannins based on their activative effect on the $\mathrm{Cu}(\mathrm{II})$ catalytic oxidation of rhodamine $6 \mathrm{G}$ by hydrogen peroxide," Analytica Chimica Acta, vol. 455, no. 2, pp. 187-191, 2002.

[9] S. L. Feng, J. M. Tang, and J. Fan, "Study on the kinetic fluorimetric determination of tannins in tea," Spectroscopy and Spectral Analysis, vol. 23, no. 2, pp. 322-324, 2003.

[10] C. Zhao, J. Zhang, and J. Song, "Flow injectionbiamperometric determination of tannin in tea," Chinese Journal of Analytical Chemistry, vol. 30, no. 2, pp. 210-213, 2002.

[11] L. J. Xu, N. Y. He, J. J. Du, Y. Deng, Z. Y. Li, and T. Wang, "A detailed investigation for determination of tannic acid by anodic stripping voltammetry using porous electrochemical sensor," Analytica Chimica Acta, vol. 634, no. 1, pp. 49-53, 2009.

[12] J. L. Guo, G. Q. Guo, Y. Q. Cai, and Y. L. Liu, "Determination of tannic acid in Phyllanthus emblica L. by high performance liquid chromatography," Chinese Journal of Spectroscopy Laboratory, vol. 24, no. 5, pp. 911-913, 2007.

[13] B. Zywicki, T. Reemtsma, and M. Jekel, "Analysis of commercial vegetable tanning agents by reversed-phase liquid chromatography-electrospray ionization-tandem mass spectrometry and its application to wastewater," Journal of Chromatography A, vol. 970, no. 1-2, pp. 191-200, 2002.

[14] I. Fecka and W. Cisowski, "TLC determination of tannins and flavonoids in extracts from some Erodium species using chemically modified stationary phases," Journal of Planar Chromatography, vol. 15, no. 6, pp. 429-432, 2002.

[15] T. P. Shen, S. B. Yao, and X. H. Huang, "Determination of tannin in tannin-cod liver oil ointment by complexometric titration," Journal of Pharmaceutical Practice, vol. 24, no. 2, pp. 99-100, 2006.

[16] H. P. S. Makkar, R. K. Dawra, and B. Singh, "Protein precipitation assay for quantitation of tannins: determination of protein in tannin-protein complex," Analytical Biochemistry, vol. 166, no. 2, pp. 435-439, 1987.

[17] L. Wei, X. S. Zhang, J. Huang, Y. H. Xie, and K. Xiao, “Online determination of tannic acid in leather wastewater by flow injection spectrophometry," Journal of the Society of Leather Technologies and Chemists, vol. 92, no. 3, pp. 127-129, 2008. 


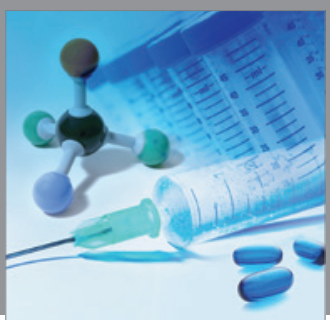

International Journal of

Medicinal Chemistry

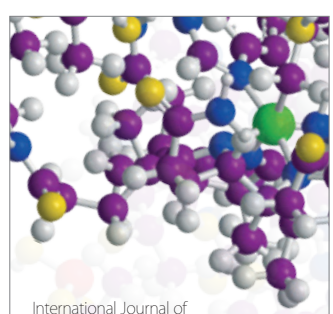

Carbohydrate Chemistry

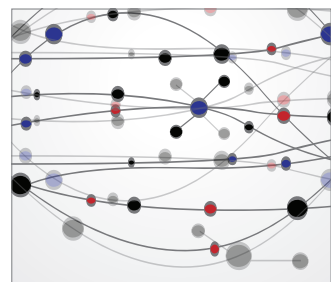

The Scientific World Journal
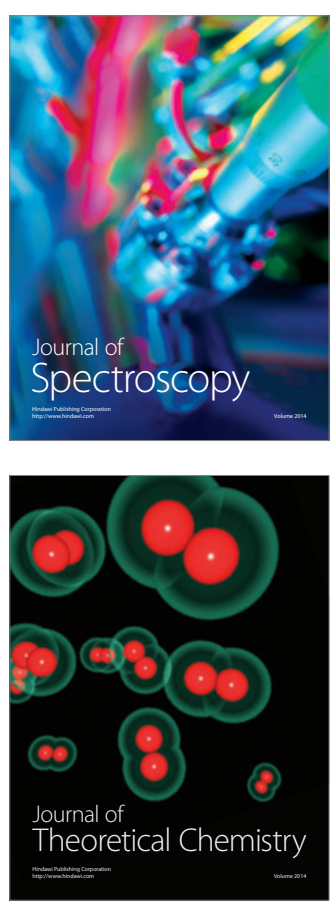
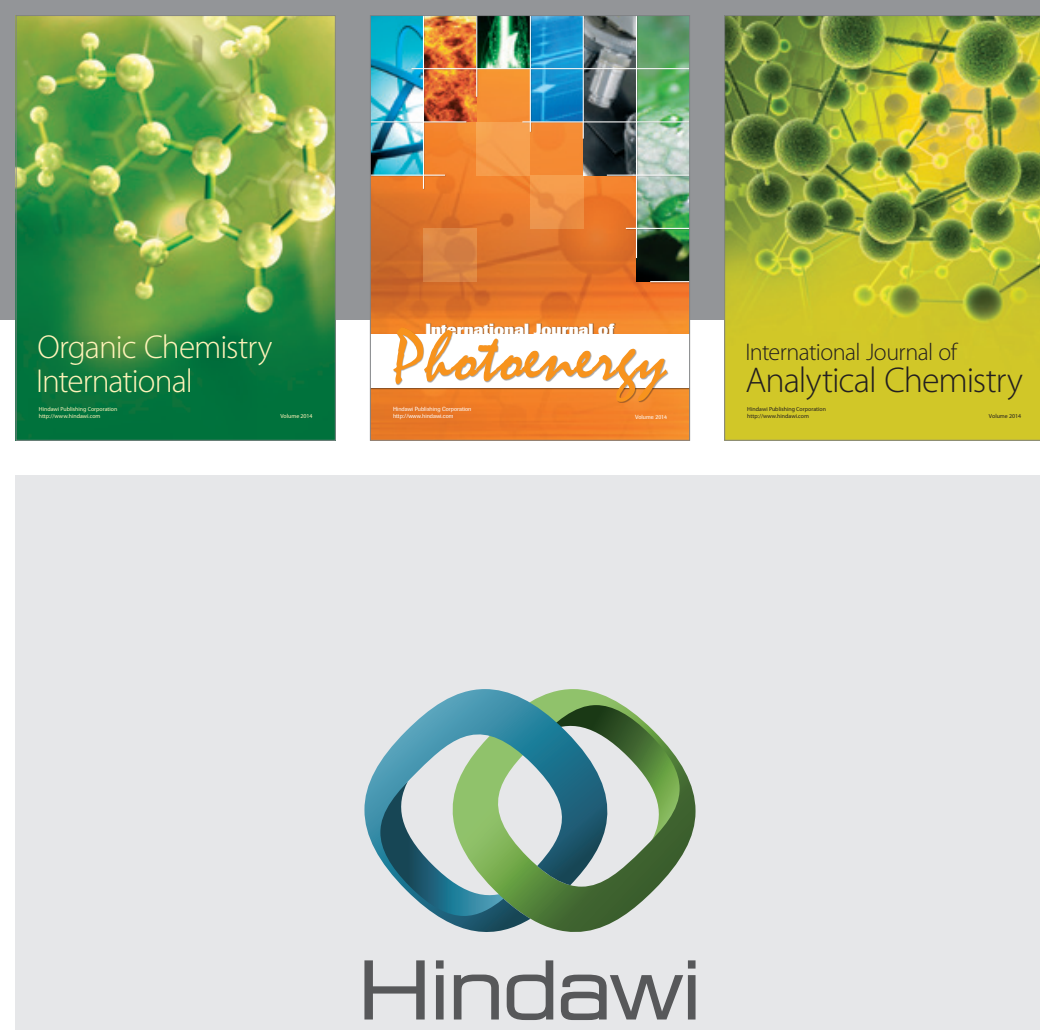

Submit your manuscripts at

http://www.hindawi.com
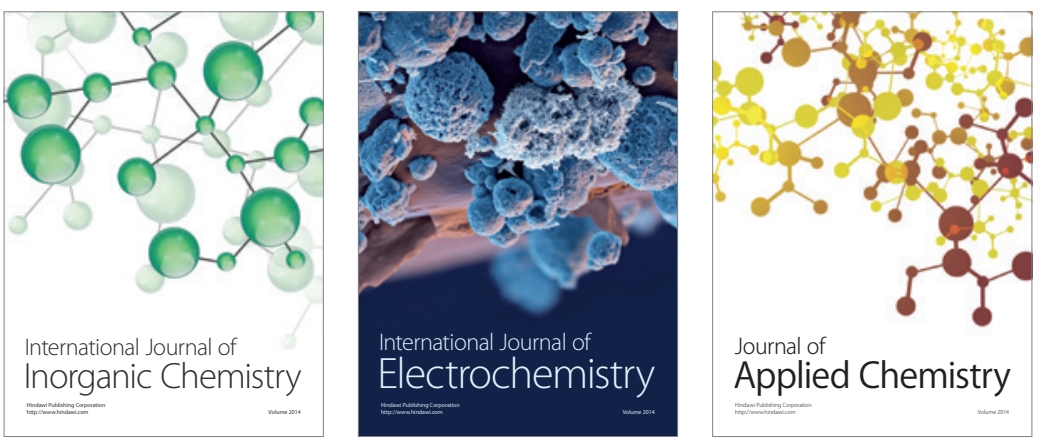

Journal of

Applied Chemistry
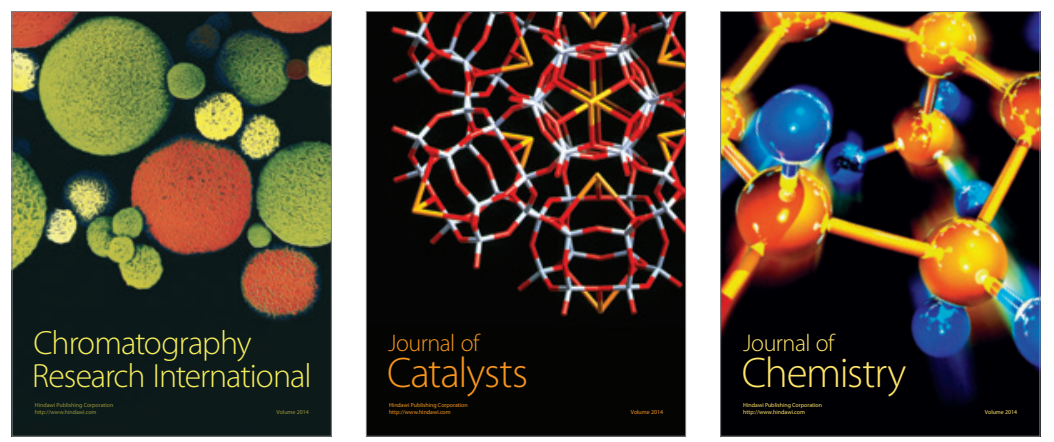
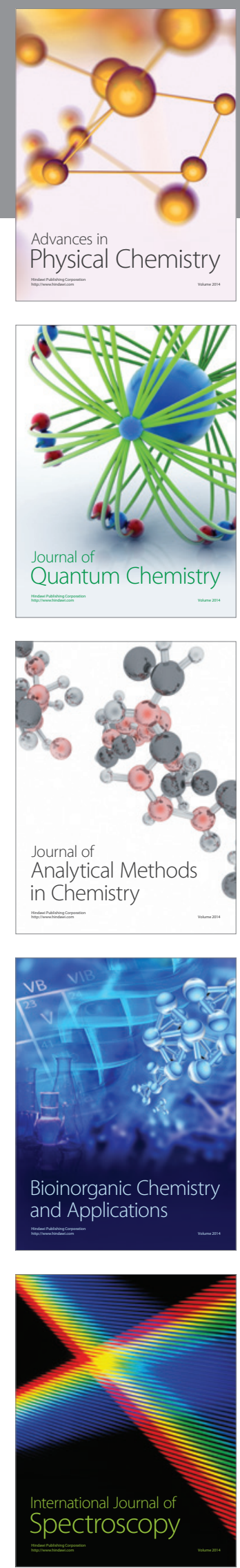